\title{
Seroprevalence of Cytomegalovirus (CMV) among Blood Donors at Bowen University Teaching Hospital Ogbomoso
}

\author{
Oladipo E.K. ${ }^{1, *}$, Akinpelu O.O. ${ }^{2}$, Oladipo A.A. ${ }^{3}$, Edowhorhu G. ${ }^{4}$ \\ ${ }^{1}$ Department of Pure and Applied Biology (Microbiology / Virology Unit), Ladoke Akintola University of Technology, Ogbomoso, Nigeria \\ ${ }^{2}$ Haematology Department, College of Health Sciences, Ladoke Akintola University of Technology, Ogbomoso, Nigeria \\ ${ }^{3}$ Department of Haematology and Blood Transfusion Services, Obafemi Awolowo University Teaching, Hospital Complex, Ile- Ife, Nigeria \\ ${ }^{4}$ Department of Laboratory Medicine, Bowen University Teaching Hospital, Ogbomoso, Nigeria \\ *Corresponding author: koladipo2k3@yahoo.co.uk
}

Received January 02, 2014; Revised January 30, 2014; Accepted May 23, 2014

\begin{abstract}
This study was designed to determine the seroprevalence of Cytomegalovirus (CMV) among blood donors at Bowen University Teaching Hospital (BUTH), Ogbomoso, Oyo State, Nigeria. Three hundred (300) consenting potential blood donors were recruited between April and September, 2012 into the study. Each subject was screened for HIV, HBsAg and HCV and structured questionnaire was administered. A total of 93(male = 63; Female $=30$ ) subjects with mean age of $45 \pm 2.3$ years previously tested negative to HIV, HBsAg and HCV were screened for CMV using Enzyme Linked Immunosorbent Assay (ELISA). Twenty-six (28.0\%) were positive for anti-CMV IgM and Twenty-four (25.8\%) were positive for anti- CMV IgG. The prevalence of anti- CMV IgM was highest in the age range 18-24 (45.5\%), female (43.3\%), single (31.4\%), student (37.8\%), and donors who have not been transfused (27.8\%). The prevalence of anti- CMV IgG was highest in the age range 18-24 (39.4\%), female (35.1\%), single (25.5\%), student (35.1\%), and donors who have not been transfused (25.6\%). The IgG+IgM- has a mean value of 3.0 which is significantly different from that of IgG-IgM+ antibody with a mean value of 5.0 These results provide more and further evidence that cytomegalovirus is present among blood donors at BUTH, and that immunocompromised individual that has been transfused with the infected blood or blood products are at risk of been infected with the virus. This also confirms that the virus spreads through blood transfusion.
\end{abstract}

Keywords: Bowen, cytomegalovirus, Immunoglobulin, seroprevalence, Ogbomoso

Cite This Article: Oladipo E.K., Akinpelu O.O., Oladipo A.A., and Edowhorhu G., "Seroprevalence of Cytomegalovirus (CMV) among Blood Donors at Bowen University Teaching Hospital Ogbomoso.” American Journal of Medical and Biological Research, vol. 2, no. 3 (2014): 72-75. doi: 10.12691/ajmbr-2-3-1.

\section{Introduction}

Cytomegalovirus (CMV), an ubiquitous agent, is a beta-herpes virus. It is a double stranded DNA virus that is transmitted by sexual contact, infected blood, saliva or urine. The virus has the ability to enter latency after asymptomatic infection in immunocompetent individuals. Transfusion-transmitted cytomegalovirus infection is associated with considerable morbidity and mortality in at-risk populations such as AIDS patients, CMVseronegative neonates and organ transplant recipients. $\mathrm{CMV}$ infection is widespread in developing countries and areas where socio-economic conditions are poor [4]. CMV is one of the most common causes of congenital malformations resulting from viral intrauterine infection in developed countries [8]. About 3\% of healthy donors are actively infected with the virus at the time of donation [3]. The prevalence of CMV tends to be lower in developed countries than in developing countries [1]. Besides contact with seropositive mothers (passage through genital tract, breast milk, etc.), blood transfusion is the most important mode of perinatal / post-natal transmission of CMV to neonates.

The description of cytomegalovirus transmission by blood transfusion and body fluids has provoked a greatly heightened emphasis on two fundamental objectives: safety and protection of human life. Transfusion transmissible infections (TTIs) are a very serious complication of blood transfusion [10]. These infections continue to pose a great challenge to transfusion medicine, especially in Africa, due to a high transfusion demand [10]. This study was carried out to investigate the seroprevalence of CMV infection among blood donors using the laboratory diagnostic techniques of anti-CMV Immunoglobulin M(IgM) and anti-CMV Immunoglobulin G (IgG).

\section{Materials and Methods}

\subsection{Study Population.}


Blood samples for testing were obtained from potential donors at the Blood Bank of the Bowen University Teaching Hospital, Ogbomoso, which registers an average of 20 family replacement donors daily. All consenting donors were recruited consecutively between AprilSeptember, 2012. Approval was obtained from the hospital's research and ethics committee. Participants were asked to and helped to fill the structured questionnaires, including demographic information, history of previous exposure to blood transfusion and donation. The exclusion criteria were: any history of chronic illness (e.g. hypertension, etc.), ages below 18 years or above 59 years (required age for blood donation) and seropositivity to HIV, HBV and HCV.

A total of three hundred (300) potential blood donors were asked to participate in the study. They were subjected to HIV, HBV and HCV rapid screening test before recruiting them into the CMV study. HIV testing was carried out using Determine HIV $1 / 2^{\mathrm{TM}}$ Test Kit (by Abbott Japan Co., Ltd. Minto-Ku, Tokyo, Japan) and HBV and HCV Test Kit (by AbonBiopharm, Hangzhou Co. Ltd, China).

\subsection{Sample Collection and Analysis}

Out of the three hundred donors, 93 participants were qualified to take part in the study. A blood sample of $5 \mathrm{mls}$ was collected into a sterile, plain bottle which was centrifuged at 3,000 rpm for 10 minutes. The serum was separated into sterile cryovials and stored at $-20^{0} \mathrm{C}$ prior to analysis.

The qualified participants' sera were tested for IgM and IgG CMV by the Enzyme -Linked Immunosorbent Assay (ELISA) test. The CMV-specific IgM / IgG antibodies were studied by the commercial WKEA Med Supplies Corp, CMV IgM/ IgG ELISA Kit (China), according to the manufacturer's instructions. All the specimens were analyzed using the enzyme immunoassay test. The presence or absence of CMV IgM/IgG was determined by comparing the sample absorbance with the absorbance of the cut-off calibrator. The data obtained were subjected to descriptive statistical analysis using SPSS version 17.0 (SPSS Inc Chicago, III, USA).

\section{Results}

Figure 1 shows prevalence of CMV antibodies in the study subjects. Out of 93 subjects whose sera were tested using ELISA, 26 (28.0\%) were positive for IgM and 24 (25.8\%) were positive for IgG. The mean age of the subjects was $45 \pm 2.3$ years. The highest prevalence of antiCMV IgM (45.5\%) was found in persons whose ages were between 18-24 years and the highest prevalence of antiCMV IgG (39.4\%) was also found in person whose ages were between 18- 24 years (see Figure 2). The sex distribution of the study subjects tested for CMV antibody is shown in Table 1. Out of 63 males, 13 (20.6\%) were positive for anti-CMV IgM and13 (20.6\%) were positive for anti-CMV IgG. Among the 30 females, 13 (43.3\%) were positive for anti-CMV IgM and 11 (36.7\%) were positive for anti-CMV IgG while 2 females had anti-CMV IgM antibodies without the anti-CMV IgG antibodies. The prevalence of CMV antibody in married and single subjects is shown in Table 2. Out of 42 married study subjects 10 (23.8\%) had anti-CMV IgM in their sera, and $11(26.2 \%)$ were positive to anti-CMV IgG. Out of 51 single subjects, 16 (31.4\%) were positive for anti-CMV IgM and 13 (25.5\%) were positive for anti-CMV IgG respectively. The prevalence of CMV antibody in different occupational groups (civil servant, student, artisan and trading) is shown in Table 3 . Out of 22 civil servant, 5 (22.7\%) were positive for anti- CMV IgM and 4 (18.2\%) were positive for anti-CMV IgG. Out of 37 students, 14 (37.8\%) were positive for anti- CMV IgM and 13 (35.1\%) were positive for anti- CMV IgG. Out of 14 artisans, 4 (28.6\%) were positive for anti- CMV IgM and 3 (21.4\%) were positive for anti- CMV IgG. Out of 20 traders, 3 (15.0\%) were positive for anti- CMV IgM and 4 (20.0\%) were positive for anti- CMV IgG.

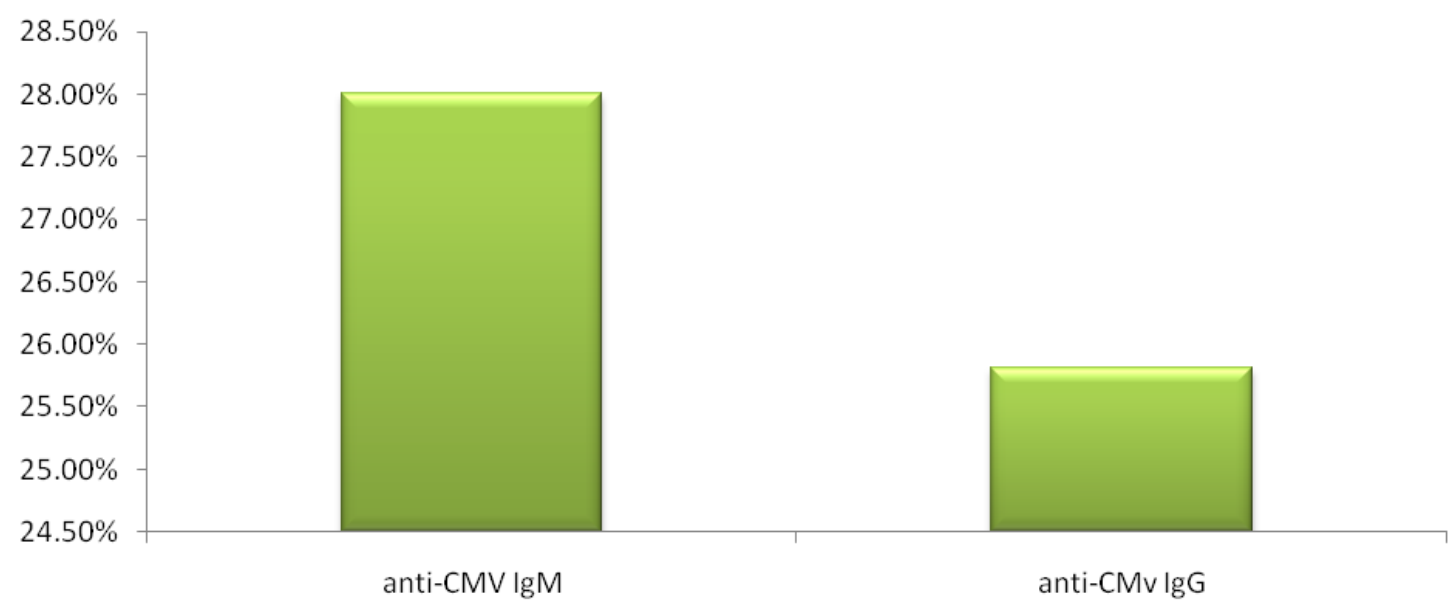

Figure 1. Seroprevalence of CMV Antibodies in Study Population

Table 1. Sex Distribution of Cytomegalovirus (CMV) antibody among the study subjects

\begin{tabular}{|c|c|c|c|}
\hline Sex & No of Subjects Tested (\%) & No of anti-CMV IgM Positive Subjects (\%) & No of anti- CMV IgG Positive Subjects (\%) \\
\hline Male & $63(67.7)$ & $13(20.6)$ & $13(20.6)$ \\
Female & $30(32.3)$ & $13(43.3)$ & $11(36.7)$ \\
\hline Total & $\mathbf{9 3}$ & $\mathbf{2 6}$ & $\mathbf{2 4}$ \\
$\mathbf{( \% )}$ & $\mathbf{( 1 0 0 )}$ & $\mathbf{( 2 8 . 0 )}$ & $\mathbf{( 2 5 . 8 )}$ \\
\hline
\end{tabular}




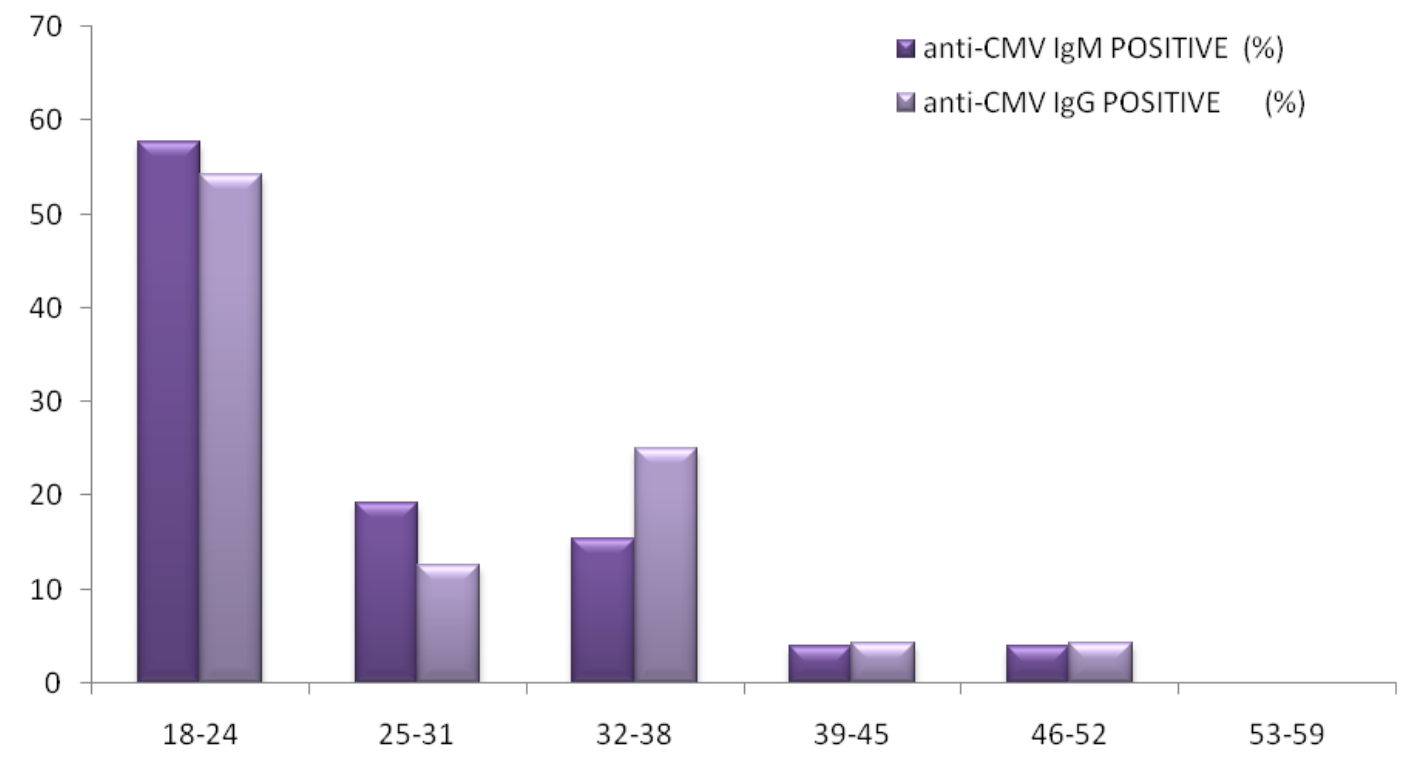

Figure 2. Age Distribution of Cytomegalovirus (CMV) antibodies among the study subjects

Table 2. Marital Distribution of Cytomegalovirus (CMV) antibody among the study subjects

\begin{tabular}{|c|c|c|c|}
\hline Marital Status & No of Subjects Tested (\%) & No of anti-CMV IgM Positive Subjects (\%) & No of anti- CMV IgG Positive Subjects (\%) \\
\hline Married & $42(45.2)$ & $10(28.8)$ & $11(26.2)$ \\
Single & $51(54.8)$ & $16(31.4)$ & $13(25.5)$ \\
\hline Total & $\mathbf{9 3}$ & $\mathbf{2 6}$ & $\mathbf{2 4}$ \\
$\mathbf{( \% )}$ & $\mathbf{( 1 0 0 )}$ & $\mathbf{( 2 8 . 0 )}$ & $\mathbf{( 2 5 . 8 )}$ \\
\hline
\end{tabular}

Table 3. Occupational Distribution of Cytomegalovirus (CMV) antibody among the study subjects

\begin{tabular}{|c|c|c|c|}
\hline OCCUPATION & No of Subjects Tested (\%) & No of anti-CMV IgM Positive Subjects (\%) & No of anti- CMV IgG Positive Subjects (\%) \\
\hline Civil Servant & $22(23.7)$ & $5(22.7)$ & $4(18.2)$ \\
Student & $37(39.8)$ & $14(37.8)$ & $13(35.1)$ \\
Artisan & $14(15.1)$ & $4(28.6)$ & $3(21.4)$ \\
Traders & $20(21.5)$ & $3(15.0)$ & $4(20.0)$ \\
\hline TOTAL & $\mathbf{9 3}$ & $\mathbf{2 6}$ & $\mathbf{2 4}$ \\
$\mathbf{( \% )}$ & $\mathbf{( 1 0 0 )}$ & $\mathbf{( 2 8 . 0 )}$ & $\mathbf{( 2 5 . 8 )}$ \\
\hline
\end{tabular}

Table 4 shows the prevalence of anti-CMV IgM and anti-CMV IgG among study subjects that had history of blood transfusion and those who did not have. Out of 3 individuals with previous history of blood transfusion 1(33.3\%) were positive for anti-CMV IgM and anti-CMV IgG, respectively. Among 90 without previous history of transfusion 25 (27.8\%) were positive for anti-CMV IgM and $23(25.6 \%)$ were positive for anti-CMV IgG

respectively. There is a significant difference in the mean value of the seropositive groups as shown in Table 5. The IgG+IgM- has a mean value of 3.0 which is significantly different from that of IgG-IgM+ antibody with a mean value of 5.0; IgG-IgM- in the mean value of the seronegative group with 90.0 mean value for the IgG+IgM- antibody, 71.0 for IgG+IgM+, 73 for IgG IgM- and 88 for IgG -IgM+ antibody.

Table 4. Distribution of Cytomegalovirus(CMV) antibody among study subjects with or without transfusion history

\begin{tabular}{|c|c|c|c|}
\hline $\begin{array}{c}\text { HISTORYOF } \\
\text { TRANSFUSION }\end{array}$ & No of Subjects Tested (\%) & $\begin{array}{c}\text { No of anti-CMV IgM Positive } \\
\text { Subjects (\%) }\end{array}$ & $\begin{array}{c}\text { No of anti- CMV IgG Positive } \\
\text { Subjects (\%) }\end{array}$ \\
\hline Yes & $3(3.2)$ & $1(33.3)$ & $1(33.3)$ \\
No & $90(96.8)$ & $25(27.8)$ & $23(25.6)$ \\
\hline TOTAL & $\mathbf{9 3}$ & $\mathbf{2 6}$ & $\mathbf{2 4}$ \\
(\%) & $\mathbf{( 1 0 0 )}$ & $\mathbf{( 2 8 . 0 )}$ & $\mathbf{( 2 5 . 8 )}$ \\
\hline
\end{tabular}

Table 5. Variance Analysis for serological patterns of Cytomegalovirus (CMV) antibody among blood donors

\begin{tabular}{|c|c|c|c|c|}
\hline GROUP & IgG +IgM- & IgG +IgM+ & IgG -IgM- & IgG- IgM+ $^{\text {IgM }}$ \\
\hline Seropositve & $3.0 \pm 0.06^{\mathrm{a}}$ & $22.0 \pm 0.12^{\mathrm{d}}$ & $20.0 \pm 0.09^{\mathrm{c}}$ & $5.0 \pm 0.03^{\mathrm{d}}$ \\
\hline Seronegative & $90.0 \pm 0.06^{\mathrm{d}}$ & $71.0 \pm 0.01^{\mathrm{a}}$ & $73.0 \pm 0.03^{\mathrm{b}}$ & $88.0 \pm 0.02^{\mathrm{c}}$ \\
\hline
\end{tabular}

Values = means scores \pm standard error

Mean values followed by the same superscript in the row are not significantly different by Duncan's Multiple Range test ( $\mathrm{p} \leq 0.05$ )

\section{Discussion}

Although blood transfusion saves millions of lives worldwide each year, recipients of the blood or blood product transfusions stand the risk of becoming infected with blood-borne diseases such as Cytomegalovirus (CMV) through transfusion of infected blood and blood products. In this study 93donors were recruited into the study with ages ranging from age 18 to 59 years which is the recommended standard for prospective donors. This 
explains why no study subject was below age 18 and only a few were above 50 years old. The overall prevalence of anti-CMV IgM (28\%) and IgG (25.8\%) is higher in compare with the overall prevalence in USA (6\%) [5], though this is lower in comparison to seroprevalence data by Staras et al., that shows that in a US based study, CMV seroprevalence increased from $36 \%$ in 6 to 11 years to $91 \%$ [9]. The subjects in the age range18 - 24 had the highest CMV antibody in the study and as this age range represents the most active age group of the study subjects, this could indicate that this is the age range that CMV infection commonly develops. Out of all the age ranges, age 32 - 38 had moreanti-CMV IgG antibodies than antiCMV IgM antibodies. This is an indication of past infections among this age range. There was a predominance of males among the study subjects because females are not encouraged to donate blood in Nigerian society. There is no significant difference between the sex seroprevalence of CMV among the subjects. Two females had anti-CMV IgM antibodies without the anti-CMV IgG antibodies which is an indication of recent infection. The results of the study also showed that majority of the donors are students. Prevalence of anti-CMV IgM 26 (28.0\%) and anti-CMV IgG 24 (25.8\%) in this study was significantly higher among the single subjects than in married individuals. Higher prevalence values for antiCMV IgM and anti-CMV IgG in single may be due to the fact that the singles individuals are more likely to engage in behaviours that put them at risk of all these infections than the married subjects. Akinbami et al.,(2009) [2], found 96\% CMV IgG among blood donors in Lagos and $100 \%$ by Krech in Ibadan [6], all these findings are higher than the seroprevalence of CMV IgG which is $25.8 \%$ found in Ogbomoso. The 28\% CMV IgM found in this study is higher than that of Akinbamiet al.,(2009)who found 19.5\% CMV IgM in Lagos and that of Pal et al.,(1972) who also found $0 \%$ in India [2,7]. From the study it was observed that there are recent infections of CMV from the variance analysis conducted. The observed seroprevalence of anti-CMV antibodies among the potential blood donors in Bowen University Teaching Hospital may provide information on the incidence of the infection in our society. It has emphasized the need of continuous epidemiological surveillance that would help in decision policy making concerning blood safety.

Results of this study which showed that the prevalence of anti-CMV IgM / IgG antibodies of $28.0 \%$ and $25.8 \%$ respectively suggest that this virus is one of the major transfusion transmissible viral infections and thus, still poses a major challenge for blood safety. Infections are more common among youth; this suggests that infection control measures should especially be targeted at the youth.

In conclusion, there is high seroprevalence of antiCMV IgM antibodies among the blood donors than the anti-CMV IgG antibodies, which is an indication of recent infections by the virus.

\section{Conflict of Interest}

The authors declare that there is no conflict of interest concerning this research.

\section{Acknowledgements}

The authors acknowledge the subjects who consented to participate in the study and the entire staff of Laboratory Diagnostic Unit of Bowen University Teaching Hospital, Ogbomoso for their support during the study period.

\section{References}

[1] Adjei A.A., Armah H.P., Narter-Olaga E. (2006). Seroprevalence of Cytomegalovirus among some voluntary blood donors at the 37 Military Hospital, Accra, Ghana. Ghana Med J., 40: 99-104.

[2] Akinbami A.A., Akanmu A.S., Adeyemo T.A., Wright K.O., Dada M.O., Dosunmu A.O. (2009). Cytomegalovirus antibodies among healthy blood donors at Lagos University Teaching Hospital SAMJ,S. Afr. Med J. Vol 99 No 7.

[3] Bayer N.L., Tegtmeier G.E. (1976). The blood donor: detection and magnitude of cytomegalovirus antibody. Yale J. Biol Med; 49: 5-12.

[4] Cabau N., Coignard S., Labadie M.D., (1979). Seroepidemiology of cytomegalovirus infection during the first year of life in urban communities.Arch Dis. Child 54: 280-90.

[5] Cheeran, M. C.-J., Lokensgard, J. R., and Schleiss, M. R. (2009). Neuropathogenesis of congenital cytomegalovirus infection: Disease mechanisms and prospects for intervention. Clinical Microbiology Reviews, 22(1): 99-126.

[6] Krech U. (1973). Complement fixing antibodies against CMV in different part of the world.Bull World Health Organ 49: 103-106.

[7] Pal S.R., Chitkara N.K., Krench V., (1972). Seroepidemiology of cytomegalovirus infection in and around Chandigarh.Indian $J$ of Med Res, 60: 973-978.

[8] Stagno S., Reynolds D.W., Pass R.F. and Alford C.A. (1993). Breast milk and the risk of CMV Infection.

[9] Staras S.A, Dollard S.C., Radford K.W. (2006).Seroprevalence of Cytomegalovirus infection in the United States, 1988-1994. ClinInfec Dis, 43: 1143.

[10] Taylor G.H. (2003). "Cytomegalovirus". AmFam Physician67 (3): 519-24. 